\title{
INSTITUIÇÕES E A RELAÇÃO ENTRE ECONOMIA E SOCIOLOGIA
}

\author{
DAVID DEQUECH* \\ Universidade Estadual de Campinas
}

Submetido em Julho 2010; aceito em Dezembro 2010

\section{Resumo}

Este artigo discute a relação entre economia e sociologia, destacando as instituições, entre outros objetos sociais de estudo. O artigo mostra como é difícil separar a economia e a sociologia quando esta última estuda assuntos econômicos. Separar economia e sociologia econômica, definindo cada campo em termos de uma abordagem, não funciona porque existem diferentes abordagens no interior de cada uma delas, assim como semelhanças entre algumas abordagens da economia e outras da sociologia econômica. É melhor definir economia e sociologia econômica em termos de um objeto amplo de estudo, mas isso não implica sua separação, porque o econômico é social e, em particular, institucional. As instituições estão dentro do econômico e dos próprios agentes econômicos, por afetarem profundamente suas motivações e sua cognição. Por outro lado, é possível diferenciar algumas práticas de economistas e sociólogos econômicos. De qualquer modo, a distinção mais importante é uma entre abordagens e não entre disciplinas.

\section{Palavras-Chave}

economia, sociologia econômica, instituições

\section{Abstract}

This article discusses the relation between economics and sociology, highlighting institutions among other social objects of study. The article points out several difficulties in distinguishing economics from sociology when the latter studies economic issues. Separating economics and economic sociology by defining each of them in terms of an approach does not work because there are different approaches within each, as well as similarities across these disciplines. It is better to define economics and sociology in terms of a broad subject matter, but this does not imply separating them, because the economic is social and, in particular, institutional. Institutions are inside the economy and inside economic agents themselves, influencing their motivations and cognition. On the other hand, one can distinguish some

\footnotetext{
* Professor do Instituto de Economia da Universidade Estadual de Campinas - Unicamp - SP - Caixa Postal: 6135 CEP: 13083-857-Email dequech@eco.unicamp.br.

Esta é uma versão revisada de um texto preparado para o seminário lusobrasileiro "Economia e Interdisciplinaridade(s)", Universidade Federal Fluminense, abril de 2010. O autor agradece os comentários recebidos naquela ocasião, bem como a dois pareceristas e o editor Renato Colistete. Esta pesquisa recebeu apoio financeiro do CNPq (bolsa PQ).
} 
practices of economists and economic sociologists. Anyway, the most important distinction is one between approaches and not one between disciplines.

Keywords: economics, economic sociology, institutions

JEL classification codes: A12, Z1, B5

\section{Introdução}

Qual é a relação entre a economia e outras disciplinas das chamadas ciências sociais? A resposta a esta questão depende da resposta a outras perguntas. O que define a economia como disciplina? Quando as outras disciplinas sociais estudam algo econômico (como a sociologia econômica, a história econômica, etc), o que as aproxima e o que as separa - se é que algo as separa - da economia? O presente texto tem como objetivo discutir essas questões, destacando dois aspectos: a) entre as disciplinas, a relação entre a economia e a sociologia, em particular a sociologia econômica; e b) entre os objetos de estudo no mundo social, as instituições, a que os economistas vêm dedicando crescente atenção. A principal contribuição pretendida pelo artigo é dupla: apontar várias dificuldades e limitações envolvidas nas tentativas de separação entre a economia e outras disciplinas das ciências sociais, particularmente a sociologia; e usar as instituições para mostrar que o social está dentro do econômico e dos próprios agentes econômicos, o que aproxima de modo fundamental a economia da sociologia econômica.

O texto está organizado da seguinte maneira. Após a introdução, a segunda seção apresenta um breve panorama histórico de como a economia tem-se relacionado com a sociologia e de como isso é afetado pelas variações do interesse ou desinteresse dos economistas pelas instituições. A terceira sessão discute algumas dificuldades para diferenciar sociologia econômica e economia se cada uma delas é definida em termos de uma abordagem teórica ou metodológica. A quarta sessão examina a identificação de um objeto de estudo como o critério mais adequado de definição da economia e da sociologia econômica e mostra como isso aproxima muito essas duas disciplinas, gerando outras dificuldades para quem quiser separá-las. É nesta discussão que as instituições aparecem com maior importância. ${ }^{1}$ A quinta sessão considera a alternativa mais modesta de definir economia e sociologia econômica como aquilo que seus praticantes fazem, respectivamente. Finalmente, a sexta sessão contém comentários a título de conclusão.

\footnotetext{
${ }^{1}$ Destaco instituições por sua importância e porque tenho mais capacidade de comentá-las, em função de minha experiência de pesquisa, sem implicar que sejam necessariamente mais importantes que outros aspectos.
} 


\section{Instituições e a Relação entre Economia e Sociologia na Academia: Uma Visão Histórica}

Até o final do século XIX, economia e sociologia não existiam como disciplinas separadas. Vista como parte das chamadas "ciências morais", a economia política clássica (assim como sua crítica marxista) certamente se interessava muito por instituições, mesmo quando esse último termo não era usado com muita frequência. Por volta de 1870 emergiu a economia neoclássica, que tentou aproximar a economia da física, afastando-a do que viriam a ser as outras ciências sociais. Por outro lado, na virada do século XIX para o XX, surgiu nos Estados Unidos a escola institucionalista de Veblen e outros, que alcançou um status importante na academia norte-americana durante algumas décadas, tendo participado da economia mainstream da época naquele país. ${ }^{2}$ De sua parte, a sociologia - aplicada ou não ao estudo da economia ou das organizações sempre se interessou por instituições, ao lado de outros aspectos do social. Além disso, os principais fundadores da sociologia - Marx, Durkheim e Weber - foram todos eles sociólogos econômicos, de modo que se pode falar hoje da sociologia econômica clássica. Parte da economia era, então, próxima da sociologia econômica e de outras disciplinas sociais, enquanto outra parte nem tanto.

Em meados do século XX, a divisão de trabalho entre a economia e outras ciências sociais já havia se alterado bastante, sobretudo nos Estados Unidos e, a partir deles, em outros países. Numa medida significativa, assuntos econômicos passaram a ser o território de economistas e não de outros cientistas sociais (Swedberg e Granovetter, 2001; Velthuis, 1999; Hodgson, 2001: 195-197). Dentro da sociologia, em particular, a sociologia econômica tornou-se muito menos frequentemente praticada. Do lado da economia, o auge dessa separação correspondeu à ascensão e hegemonia teórica do modelo standard de equilíbrio geral, também conhecido como modelo "Arrow-Debreu". Este modelo é substancialmente a-histórico e ainstitucional, ao menos no que se refere às suas hipóteses explícitas (voltaremos a isso mais adiante). Numa das interpretações possíveis, o modelo "Arrow-Debreu" pretende valer para qualquer economia, em qualquer lugar e em qualquer momento do tempo. Numa leitura um pouco menos geral, o modelo só supõe claramente uma única instituição e mesmo assim a entende de forma extremamente restritiva: o mercado, mas não um mercado próximo a mercados reais e sim um mercado imaginário, reduzido ao mecanismo de preços (a interação entre oferta e demanda). Outras instituições, incluindo algumas sem as quais mercados reais não podem existir, são ignoradas explicitamente. Naquele período, a economia mainstream afastou-se de outras disciplinas sociais e aproximou-se das ciências exatas e da matemá-

\footnotetext{
${ }^{2}$ Adota-se aqui o conceito sociológico de economia mainstream proposto em Dequech (2007-2008: 281): "mainstream economics is that which is taught in the most prestigious universities and colleges, gets published in the most prestigious journals, receives funds from the most important research foundations, and wins the most prestigious awards". Este conceito geral pode ser aplicado a diferentes períodos históricos e a diferentes países.
} 
tica, mais ainda do que os fundadores da economia neoclássica haviam feito. Por volta da década de setenta do século XX, as barreiras que separavam a economia de outras disciplinas sociais começaram a diminuir. Da parte dos economistas, três movimentos podem ser notados a esse respeito:

Primeiro (sem ordem cronológica ou de importância) houve na economia uma virada institucional: ressurgiu o interesse dos economistas pelas instituições. Isso vale inclusive para os economistas neoclássicos e, dentro desse conjunto, para teóricos de equilíbrio geral que foram além do modelo standard. De fato, algumas tentativas de ultrapassar os limites do modelo "Arrow-Debreu" e ampliar o escopo da teoria de equilíbrio geral levaram à incorporação de mais instituições à análise. Além disso, surgiu a chamada nova economia institucional (Dequech, 2006). Parte dela aplica ao estudo das instituições a teoria neoclássica, entendida aqui como assentada sobre três elementos definidores (Dequech, 2007-2008): a hipótese de racionalidade na forma de maximização de utilidade; a hipótese de que a economia analisada está em equilíbrio ou tende a um equilíbrio (que pode ser único ou um entre múltiplos equilíbrios); e um conceito de incerteza que corresponde ao "risco knightiano" (com probabilidades objetivas conhecidas) ou, mais amplamente, à incerteza tal como concebida na teoria da utilidade esperada subjetiva de Savage (1954). Outras alas da nova economia institucional abandonaram, ao menos em parte, uma ou mais dessas ideias neoclássicas básicas (Dequech, 2006). Oliver Williamson, recuperando insights de Ronald Coase sobre custos de transação, e Douglass North, são alguns nomes importantes neste contexto. Esses três autores ganharam o prêmio Nobel de economia. ${ }^{3}$ Williamson dividiu-o com a cientista política Elinor Ostrom, cuja premiação é um ótimo exemplo de como aumentou o respeito dos economistas por outras disciplinas sociais. Dentro e fora da economia neoclássica surgiram também outras abordagens às instituições, mas sem o rótulo de economia institucional (algumas serão mencionadas mais adiante). Seja sob este rótulo ou não, a esmagadora maioria dos trabalhos da economia mainstream contemporânea dedicados ao estudo das instituições está baseada em modelos matemáticos e especialmente na teoria dos jogos. Usando de novo o prêmio Nobel como indicador de eminência, cabe aqui mencionar os trabalhos sobre mecanismos de desenho institucional, que levaram à premiação conjunta de Leonid Hurwicz, Eric Maskin e Roger Myerson. A ascensão da teoria dos jogos na economia em parte se deu às expensas da teoria do equilíbrio geral. Dito de outra forma, a retomada do estudo das instituições no meio da economia mainstream em boa medida foi facilitada pelo aumento do prestígio de um aparato formal considerado propício a isso (ou, em vários casos, mais propício

\footnotetext{
${ }^{3}$ Friedrich Hayek também ganhou o prêmio Nobel (junto com Gunnar Myrdal), em parte por causa de suas contribuições sobre a interpenetração de fenômenos econômicos, sociais e institucionais. No entanto, a influência de Hayek é muito maior sobre a ala austríaca da nova economia institucional do que sobre a economia mainstream - embora North reconheça um débito a ele. Outro nome a mencionar é o de James Buchanan, que ganhou o Nobel por suas contribuições sobre as bases contratuais e constitucionais das decisões econômicas e políticas (isso se relaciona com as bases institucionais dos mercados, discutidas mais adiante).
} 
que a teoria do equilíbrio geral): a teoria dos jogos. A virada institucional levou a uma aproximação com outras disciplinas, sobretudo o direito e a história. O aproveitamento de contribuições da sociologia é bem maior na economia não mainstream, mas há exceções de destaque, como Masahiko Aoki (2001), Avner Greif (2006), Durlauf e Young (orgs.)(2001) e George Akerlof (1984), embora esse último use ideias da sociologia e da antropologia ao mesmo tempo em que amplia o escopo da hipótese de maximização da utilidade, com referências a costumes, identidade e normas sociais no tratamento de temas tradicionalmente econômicos.

Segundo, houve na economia uma virada cognitiva: ressurgiu o interesse dos economistas por questões cognitivas, referentes em especial a certos tipos de incerteza e de possíveis limitações mentais e computacionais dos agentes econômicos. Na economia mainstream, isso se deu em larga medida em reação à intervenção no debate econômico de autores oriundos de fora da disciplina e em particular influenciados pela psicologia. Destacam-se aqui os mais influentes precursores da economia comportamental: Herbert Simon, de um lado, e os psicólogos Daniel Kahneman e Amos Tversky, de outro. Simon e Kahneman ganharam o prêmio Nobel (Tversky certamente o teria compartilhado com Kahneman se estivesse vivo no momento da premiação). ${ }^{4}$ Embora Simon se interessasse muito por organizações e, em grau menor, por outras instituições, a economia comportamental em geral não tem dado tanta atenção às instituições ou, mais amplamente, ao contexto social em que operam os agentes econômicos (ver Dequech, 2007-2008 para algumas referências críticas ao individualismo das abordagens psicológicas que penetraram a economia mainstream). Uma exceção, de difusão ainda limitada, são os trabalhos comportamentais sobre justiça (fairness), envolvendo normas sociais.

Terceiro, economistas neoclássicos invadiram o território de sociólogos, cientistas políticos e outros estudiosos da sociedade, aplicando em outros campos o instrumental neoclássico, em particular a hipótese de maximização de utilidade como critério de racionalidade. Gary Becker (1976) é o principal expoente disso que ficou conhecido como “imperialismo econômico". Seja em reação a isso ou não, não economistas voltaram a dedicar com intensidade sua atenção a assuntos econômicos. Dentro da sociologia, em particular, emergiu a partir dos anos 1980 a chamada nova sociologia econômica. Inicialmente, sob a influência de Mark Granovetter, ela concentrou-se bastante nas redes de relações interpessoais. Com o passar do tempo, outros aspectos sociais da economia passaram a ser (re)examinados pelos sociólogos, incluindo as instituições.

\footnotetext{
${ }^{4}$ Hayek é, junto com Simon, um dos primeiros apóstolos da complexidade na economia, mas, de novo, sua influência sobre a economia mainstream a esse respeito (em particular sobre a economia comportamental) é bastante limitada.
} 
Assim como na economia, "novos institucionalismos" surgiram em outras disciplinas das ciências sociais. Em vários casos, eles são aplicados ao estudo de fenômenos econômicos, de um modo que enriquece nosso entendimento.

\section{Disciplinas Definidas por Abordagens? Algumas Complicações}

A sociologia econômica é definida por alguns autores influentes como um campo de estudo caracterizado por uma abordagem sociológica a fenômenos econômicos. Esta é a definição adotada, por exemplo, por Neil Smelser e Richard Swedberg (1994) em sua introdução ao Handbook of Economic Sociology. Há pelo menos dois fatores complicadores para essa definição: ${ }^{5}$

O primeiro, que reflete uma falta de consenso entre os sociólogos sobre como lidar com questões sociais, é a existência de um tipo de sociologia que aplica a questões sociais uma abordagem parcialmente tomada emprestada da economia - mais especificamente, da economia neoclássica. Essa abordagem é frequentemente denominada teoria da escolha racional, mas essa expressão também é um tanto controversa. Alguns entendem a ideia básica da teoria da escolha racional como sendo a defesa da extensão do modelo neoclássico a assuntos tradicionalmente investigados apenas por sociólogos. Para o bem da precisão, deveria ser notado que, na opinião de James Coleman (1994), a teoria sociológica da escolha racional combina elementos centrais da economia neoclássica e da sociologia. ${ }^{6}$ A maioria dos usuários da expressão "sociologia econômica" provavelmente tem em mente escolas de pensamento sociológico outras que não a teoria da escolha racional entendida assim. De fato, a sociologia econômica e a teoria da escolha racional foram identificadas como abordagens concorrentes (e.g., Swedberg, 1997; também Wacquant e Calhoun, 1989). Isso pode nos ajudar a entender a afirmativa de que a (nova) sociologia econômica é unida por uma postura negativa em relação a análises econômicas standard a fenômenos econômicos (Zukin e DiMaggio, 1990; Beckert, 1996 e, com referência à sociologia econômica francesa, Lévesque, Bourque e Forgues, 1997). ${ }^{7}$

O segundo fator complicador é a existência de abordagens não neoclássicas dentro da economia como disciplina. Assim como na sociologia não há um enorme consenso, não existe uma única “abordagem econômica”. Viviana Zelizer (2007: 1057-1058) reconhece

\footnotetext{
${ }_{6}^{5}$ Essa parte da discussão recupera alguns argumentos de Dequech (2003).

${ }^{6}$ Wacquant e Calhoun (1989) descrevem-na como uma aplicação ampliada e modernizada do que chamam de " $a$ abordagem econômica" (minha ênfase). Esta última expressão é interessante, dado que Swedberg e Granovetter se referem à "abordagem sociológica". Nos dois casos implica-se uma unidade intradisciplinar que na verdade não existe.

${ }^{7}$ Amitai Etzioni (1991) descreve a socioeconomia (socio-economics) também bastante em oposição à economia neoclássica. A relação entre sociologia econômica e socioeconomia não será considerada aqui.
} 
que a sociologia econômica não está sozinha em seu desafio a tratamentos neoclássicos de processos econômicos. Ela só menciona, no entanto, o surgimento de abordagens críticas dentro da economia após o renascimento inicial da sociologia econômica, a partir de meados dos anos 1980. Ela parece desconhecer outras abordagens não neoclássicas, em particular fora da mainstream da economia contemporânea. As diferenças entre as abordagens não neoclássicas na economia (sobretudo aquelas não mainstream) e muito da sociologia econômica nem sempre são facilmente identificáveis. A esse respeito, vale a pena mencionar em particular ao menos duas correntes de pensamento: a economia institucional na longa tradição de Veblen e Commons (frequentemente chamada de "velha" ou "original", sobretudo pelos que usam a sigla OIE em inglês) e a economia francesa das convenções (économie des conventions), que surge na mesma época que a nova sociologia econômica. ${ }^{8}$ Talvez não surpreendentemente, economistas ligados a essas duas correntes defendem, à sua maneira, uma unificação das ciências sociais (Hodgson, 1994; Orléan, 2005; Eymard-Duvernay, et alli 2006). Mesmo na economia mainstream, há abordagens que são contrárias à redução de todo comportamento econômico relevante à maximização de utilidade e que usam argumentos próximos à sociologia. É o caso de Amartya Sen $(1977,1985)$ sobre o que ele chama de comprometimento (commitment).

Esse segundo fator complicador aplica-se também à visão mais específica que Jens Beckert (1996) tem de como deveria ser a sociologia econômica: para ele, ela deveria tomar como ponto de partida a incerteza, entendida num sentido não neoclássico. Existem abordagens heterodoxas em economia que também se assentam sobre uma noção alternativa de incerteza, entre outros pilares. Para uma discussão mais detalhada sobre incerteza e sociologia econômica, ver Dequech (2003).

Assim como fazem alguns sociólogos econômicos em relação à sua subdisciplina, há economistas que definem a disciplina da economia como aquela que adota certa abordagem ou um método de análise: tipicamente, algo baseado na hipótese de maximização de utilidade. No que se refere à relação da economia com outras disciplinas, embora originalmente Becker (1976: 5) tenha usado isso para distinguir a economia de outras disciplinas em termos de abordagens, ao longo do tempo, tal concepção serviu mais para ampliar o escopo da economia, através da aplicação do que é visto como $a$ abordagem econômica. Há, no entanto, a implicação de que não praticam a verdadeira ciência econômica aqueles que não adotarem essa mesma abordagem - inclusive laureados com o Nobel, como Simon ou, pelo menos em parte de seu trabalho, Sen, além de inúmeros autores heterodoxos menos célebres.

\footnotetext{
${ }^{8}$ Nos dois casos, a proximidade com a sociologia econômica é notada também por Philippe Steiner (1999: 42, 100). Por outro lado, Olaf Velthuis (1999) discute não apenas as semelhanças, mas também as diferenças entre a sociologia econômica e a economia institucional original.
} 


\section{Disciplinas Definidas por Objetos? A Proximidade entre Economia e Sociologia Econômica}

Em contraste com a visão que define a economia em função de uma abordagem ou um método de análise, uma alternativa é defini-la em função de um objeto de estudo. Concebe-se então a economia como a disciplina que estuda a economia como objeto. Dentro dessa concepção, alguns economistas ligados à tradição institucionalista americana ofereceram um tratamento mais específico da disciplina. Walter Neale, inspirado na distinção de Karl Polanyi entre os sentidos formal e substantivo do termo "econômico", propôs o seguinte: "substantive economics ... is the study ... of how people go about provisioning themselves, whether as individuals or as members of groups with common purposes" (1987: 1180). Na definição de Allan Gruchy (1987: 21), a economia é a disciplina que estuda o processo de provisão social. Isso pode ser entendido como relacionado com a provisão das necessidades. A provisão social engloba não apenas objetos materiais, mas também serviços, incluindo cuidados pessoais. Parece razoável acrescentar que a economia deve estudar também as consequências de organizar o processo de provisão social de certa maneira. Esta definição não é livre de pontos obscuros, mas parece satisfatória e preferível a outras alternativas.

Existem variados tipos de relações econômicas através das quais as pessoas obtêm a provisão de bens e serviços. Alguns correspondem, grosso modo, às formas de integração de que tratou Polanyi $(1944,1957)$, embora não precisem ou não devam ser todas caracterizadas exatamente como ele o fez: reciprocidade, redistribuição, troca mercantil e autosubsistência familiar. Outros tipos de relação econômica incluem solidariedade sem reciprocidade, roubo e (dependendo de como se vê a forma pela qual o Estado financia seus gastos) provisão pelo Estado sem redistribuição. Se a economia estuda o econômico, a sociologia pode ser vista como a disciplina que estuda o social, como seu próprio nome indica. A subdisciplina da sociologia econômica pode ser vista como estudando simultaneamente o social e o econômico. ${ }^{9}$ Parte importante da relação entre economia e sociologia passa a depender, então, da relação entre seus objetos de estudo. $\mathrm{Na}$ verdade, esses objetos se interpenetram em grande medida. Mais especificamente, o social está inevitavelmente presente dentro do econômico. É isso que se pretende argumentar em mais detalhes a seguir e disso resulta uma enorme dificuldade para quem quiser separar economia e sociologia em termos de objetos. As instituições são uma parte importante dos argumentos. Assim, convém começar discutindo o que são as instituições e como elas afetam os indivíduos. Em seguida, as instituições serão

\footnotetext{
${ }^{9}$ Entre os principais expoentes da sociologia econômica, Neil Fligstein oferece o que pode ser visto como uma versão particular dessa definição da sociologia econômica em termos de objeto: Economic sociology is the study of how the material production and consumption of human populations depend on social processes for their structure and dynamics (2001: 6). Esta versão pode, porém, parecer muito restritiva, se for interpretada como priorizando bens materiais, em prejuízo de serviços, ou priorizando produção e consumo, em detrimento, por exemplo, da moeda e da acumulação de ativos financeiros.
} 
colocadas ao lado de outros aspectos do social. Depois disso será considerado como o social está dentro do econômico no caso particular dos mercados, dada sua relevância nas economias contemporâneas.

\section{A. Instituições}

As instituições são entendidas aqui de modo amplo, como padrões socialmente compartilhados de comportamento e/ou de pensamento (Dequech, 2009). Isso inclui padrões que não apenas são seguidos, mas também que são prescritos ou descritos - no sentido de que eles indicam ou representam o que (não) fazer ou pensar em determinadas circunstâncias - e, neste sentido, podem ser chamados de regras. Socialmente compartilhados quer dizer aqui compartilhados por razões sociais, por contraste com causas genéticas ou outro tipo de causa natural ou inevitável. O conceito de instituições tem uma dimensão comportamental, assim como uma dimensão mental. A dimensão mental inclui não apenas expectativas, mas também modelos mentais compartilhados. Existem diferentes tipos de instituição. Normas socialmente compartilhadas indicam o que um indivíduo deveria fazer, trazem consigo a possibilidade de sanções externas, mas, ao menos no caso de alguns indivíduos, são internalizadas. Normas formais ou legais são mantidas em prática em última instância pelas organizações do sistema legal, enquanto as normas sociais informais estão ligadas a sanções por outras pessoas no grupo relevante. As convenções possuem ao menos duas características que outros padrões socialmente compartilhados (sejam eles formais ou informais) podem não ter: a) quando seguida conscientemente, uma convenção é seguida ao menos em parte porque outras pessoas a seguem (ou se espera que vão seguir) e não - ou não apenas - porque há uma pressão externa; b) uma convenção é em algum grau arbitrária, no sentido de que é concebível uma alternativa hipotética que não é claramente inferior ao padrão prevalecente. ${ }^{10}$ As instituições dependem dos indivíduos que as reproduzem, transformam ou criam, mas elas também influenciam o comportamento e o pensamento individual de maneiras cruciais e às vezes constitutivas (Dequech, 2006).

Talvez o tipo menos controverso de influência das instituições seja seu papel restritivo. Seu papel cognitivo é triplo: informacional, prático e profundo. Além de dar informações (como vários economistas institucionais reconhecem), elas também incorporam ou corporificam conhecimento prático ou tácito; e, especialmente como modelos mentais compartilhados, desempenham uma função cognitiva profunda ao influenciar o modo como os indivíduos selecionam, organizam e interpretam informações. Em termos de motivações, as instituições não apenas dão incentivos, como usualmente enfatizado por

\footnotetext{
${ }^{10}$ Em Dequech (2009) está apenas implícito que a alternativa deve não ser claramente inferior ao padrão prevalecente para que este último seja arbitrário.
} 
economistas mainstream, mas também influenciam os próprios objetivos que as pessoas buscam e as obrigações que os indivíduos se atribuem. Essas são o que podemos denominar as variantes simples e profundas do seu papel motivacional, respectivamente. Finalmente, as instituições podem também desempenhar um papel emocional, menos estudado por enquanto, através do qual influenciam o estado emocional das pessoas.

Por serem tratadas como padrões de comportamento ou de pensamento socialmente compartilhados, ou seja, compartilhados por razões sociais, as instituições econômicas inevitavelmente implicam que parte do social está dentro do econômico. Quando se trata as instituições como capazes de influenciar profundamente a cognição e as motivações dos indivíduos, como discutido acima, coloca-se o institucional não apenas dentro do econômico em geral, mas, num sentido importante, dentro dos próprios agentes econômicos em particular. Um pouco mais adiante, o argumento de que o social, em particular o institucional, está dentro do econômico, será ilustrado no caso dos mercados. Em termos gerais, ele vale, contudo, qualquer que seja o tipo de economia prevalecente numa realidade histórica concreta.

\section{B. Instituições e Outros Aspectos do Social}

Émile Durkheim definiu a sociologia geral como a "ciência das instituições" (Velthuis, 1999: 634 e n. 6). Coerentemente, Durkheim concebeu a sociologia econômica como voltada ao estudo das instituições econômicas (Swedberg, 2003: 18). Essa visão é excessivamente restritiva, à luz do argumento de que as instituições não esgotam todos os aspectos relevantes do social, sendo apenas um entre outros. Quais são os outros aspectos depende da classificação de cada autor. Um aspecto, bastante destacado na sociologia econômica em seus primeiros anos de renascença, corresponde às redes de relações interpessoais (redes sociais). Outro consiste nas relações de poder (ou relações de dominação, hierarquia, etc). Elas são relações entre posições sociais, a não confundir com relações pessoais. Alguns autores incluem ainda os aspectos sociais da cognição ou as estruturas cognitivas socialmente compartilhadas (e.g., Dobbin, 2004: 4); para outros, essas estruturas são instituições e não algo separado delas (esta é a concepção adotada aqui, como já visto). Mais recentemente, um número menor de autores, ao pensar em questões econômicas, passou a identificar ainda outro aspecto do social: as técnicas performativas que eles acreditam formatar os mercados. Em suma, o social não é apenas institucional. Ao mesmo tempo, esses diferentes aspectos do social estão ligados entre si. As instituições, em particular, estão estreitamente relacionadas aos demais aspectos. Por exemplo, as redes de relações sociais servem de condutor para as instituições (Dobbin, 2004: 18) e, às vezes, para sua efetivação (enforcement). A conexão entre as instituições e as relações de poder é uma via de duplo sentido. As 
instituições são em parte mantidas por relações de poder; no caso específico das organizações, trata-se de instituições que são em parte definidas por essas relações de poder, na forma de relações hierárquicas. Por outro lado, sobretudo através de sua presumida legitimidade ou inevitabilidade, as instituições ajudam a sustentar relações de poder. Há quem enxergue o poder mesmo como a capacidade de influenciar o entendimento que os outros têm do mundo e de seus interesses. Nesse duplo sentido, a economia das instituições pode ser vista como uma economia política (o que aproxima a economia de outra disciplina social, a ciência política).

\section{O Importante Caso Particular dos Mercados}

Alguns economistas parecem restringir sua concepção da economia como disciplina ao estudo de um tipo de relação econômica, nomeadamente as relações de troca, sobretudo troca mercantil. ${ }^{11}$ As trocas através dos mercados não esgotam, entretanto, as possibilidades de provisão social, como argumentado acima. Assim, a economia como disciplina não deveria se restringir a investigar apenas os mercados.

Contudo, mesmo quando nos limitamos ao estudo dos mercados, a economia como disciplina não é facilmente separável da sociologia econômica. De acordo com Marion Fourcade (2007: 1017), a nova sociologia econômica, em suas origens nos anos oitenta do século XX, orientou-se pela ambição de um diálogo - ou uma concorrência - com a economia mainstream. Isso a teria levado a se construir dominantemente como a sociologia dos mercados. Alguns sociólogos econômicos discordam desse foco estreito (para algumas referências, ver Fligstein e Dauter, 2007: 106, n. 1 e Zelizer, 2007, além do próprio artigo de Fourcade) e o argumento de que a provisão social não se faz apenas pelos mercados lhes dá razão. De qualquer modo, repete-se aqui, agora de modo mais específico, a já apontada dificuldade mais geral de responder a seguinte pergunta: o que é distintivo da sociologia, por contraste com a disciplina da economia, no estudo de assuntos econômicos? Isso vale no caso particular em que o objeto econômico de estudo é restrito aos mercados. Também dentro dos mercados existe inevitavelmente algo de social, algo que facilmente pode ser visto como um objeto de estudo de interesse para sociólogos, às vezes até mais tipicamente interessante para sociólogos que para economistas. De fato, também no caso específico do estudo dos mercados os sociólogos têm manifestado seu interesse pelos diferentes aspectos do social já mencionados anteriormente. Fourcade (2007: 1015), por exemplo, destaca esses aspectos ao identificar quatro representações principais do que é sociologicamente importante sobre mercados: "the

\footnotetext{
${ }^{11}$ Mais restritivamente ainda, alguns economistas concebem a economia como voltada apenas para relações de troca e baseada na hipótese de maximização de utilidade ou algo semelhante. Isso combina um objeto e uma abordagem específica - e sob certos pontos de vista problemática - ao objeto.
} 
social networks that sustain them, the systems of social positions that organize them, the institutionalization processes that stabilize them, and the performative techniques that bring them into existence."

Mais particularmente, existe dentro dos mercados algo de institucional. Isso vai além do argumento de que o mecanismo de preços é uma instituição. Duas ideias principais serão destacadas aqui a esse respeito. Primeiro, será considerado o que se pode chamar de bases institucionais dos mercados, sem as quais os mercados não podem existir. Segundo, serão dadas breves indicações de como as instituições estão difundidas e são importantes numa economia de mercado, mesmo quando algumas dessas instituições não são indispensáveis à existência dos mercados.

\section{As Bases Institucionais dos Mercados}

Os mercados não apenas são instituições, mas dependem de instituições para existir.

Algumas das bases institucionais dos mercados são reconhecidas como necessárias sem que sempre se veja o seu caráter institucional. É o caso, por exemplo, da divisão social do trabalho (mesmo que esta divisão não seja capaz de atingir uma larga escala sem os mercados, que a estimulam). Seu caráter institucional resulta de sua necessária associação com modos de pensar socialmente compartilhados, em particular modos de pensar sobre a conveniência da especialização por contraste com a autosubsistência.

Outras pré-condições para a existência de mercados são frequentemente vistas como institucionais, embora talvez não como tipicamente de interesse sociológico ou mais próximo da seara dos sociólogos que dos economistas. Este parece ser o caso: da propriedade privada do que vai ser trocado; da proteção de direitos de propriedade sobre o que pode ser vendido e comprado; e do cumprimento de contratos, ao menos quando dependente da (ameaça de) pressão do Estado. ${ }^{12}$ Talvez se possa enquadrar no mesmo caso instituições que estabeleçam uma regulação básica da concorrência - no mínimo, regras sobre concorrência de bens importados, modos de pensar sobre o que é concorrência desleal (como, por exemplo, sonegação de impostos e, em casos de algum poder de mercado, dumping, vendas casadas, etc.) e a prática pelo Estado e/ou agentes privados de (in)tolerância à concorrência desleal; mais dinamicamente, regras sobre limites ou não para a market share de um ofertante ou demandante no mercado. Pelo menos para alguns autores, deve-se acrescentar também a moeda e o Estado, ao menos

\footnotetext{
12 Segundo Greif (2006), historicamente o cumprimento de contratos nem sempre foi devido ao Estado ou à preocupação de indivíduos com sua reputação pessoal. Greif refere-se a comunidades preocupadas com sua reputação coletiva.
} 
para garantir direitos de propriedade e o cumprimento de contratos ou para garantir a própria moeda. $\mathrm{O}$ mesmo parece valer para instituições que ajudam a definir o que é um determinado bem ou serviço, com sua respectiva qualidade, por contraste com outros bens e serviços.

Restam ainda outras bases institucionais dos mercados, que não são frequentemente identificadas por muitos economistas e que envolvem temas reconhecidamente sociológicos. São exatamente elas que mais claramente colocam o social dentro dos mercados. Elas podem ser reunidas em pelo menos três grupos. Primeiro, há um conjunto de regras (permissões e restrições) e modos compartilhados de pensar sobre o que pode ou não ser vendido, por quem e em que circunstâncias. Isso é o que delimita o domínio do mercado, sujeito a alterações relativamente frequentes. As instituições envolvidas são concepções normativas morais e político-ideológicas (com relação a: que tipo de bens e serviços devem ou não ser providos gratuitamente pelo Estado e não via mercados; o nacionalismo ou não em relação aos produtores nacionais e seus interesses; etc.), junto com restrições comportamentais formais (como leis) e informais (como normas sociais e convenções). Segundo, há normas sociais de honestidade e cooperação, que servem de base para a confiança (trust) nos agentes com quem se interage, junto com redes de relações interpessoais. Isso em parte se sobrepõe ao cumprimento de contratos, mas vai além, incluindo aspectos não completamente especificados nos contratos (e.g., a qualidade das mercadorias e serviços). Um terceiro grupo inclui duas instituições já mencionadas acima, mas agora vistas sob uma ótica diferente, incomum entre economistas: a moeda e o Estado. Numa visão inspirada em Polanyi, o Estado seria indispensável para administrar o que ele chamou de "mercadorias fictícias", incluindo trabalho e a terra, além da moeda. ${ }^{13}$ Uma outra visão da moeda enfatiza suas bases convencionais, mas rejeitando a ideia econômica tradicional de que o objeto a ser eleito moeda tem um valor social prévio à convenção monetária (Aglietta e Orléan, 2002).

\section{A Ubiquidade e Importância das Instituições na Vida Econômica}

Há muito mais de institucional na vida econômica do que supõe a maioria dos economistas e mesmo uma parte dos sociólogos. Menos frequentemente reconhecidas como relevantes para economistas, mas na verdade muito importantes e amplamente difundidas, são as instituições informais.

Além das instituições já mencionadas, podem-se destacar várias outras. Há, por exemplo, as instituições tecnológicas. Algumas delas são formais, como as organizações e as leis dos chamados sistemas nacionais de inovação. Outras instituições tecnológicas

${ }^{13}$ Ver Krippner e Alvarez (2007: 229-233), para referências e discussão. 
são informais: convenções e normas sociais. As convenções tecnológicas são mais facilmente perceptíveis na literatura sobre tecnologias concorrentes, path dependence e lock in, a partir dos trabalhos seminais de Brian Arthur e Paul David, mas também podem ser associadas aos chamados paradigmas tecnológicos. Pelo menos alguma interseção existe com a literatura sociológica que trata de estudos sociais da tecnologia e da construção social da tecnologia. Por sua vez, a ideia de normas sociais tecnológicas aparece já nas reflexões de Schumpeter sobre o agente inovador e ressurge com riqueza nos trabalhos que tratam das dificuldades envolvidas em path creation.

No domínio das finanças, organizações e regulamentos formais são amplamente vistos como importantes, mas cresce o reconhecimento da existência também de convenções e, por enquanto em menor grau, de normas sociais financeiras. Keynes $(1936,1937)$ ofereceu um exemplo seminal com a análise de sua convenção projetiva (que consiste em projetar para o futuro o valor presente de uma variável, como o preço das ações), mas existem modelos convencionais que são mais vagos ou gerais, no sentido de que não geram previsões específicas sobre o valor futuro de alguma variável. Um exemplo é a convenção financeira de que trata André Orléan (1999), um modelo mais qualitativo de análise que ele supõe ser adotado por operadores no mercado de ações e que é compatível com diferentes expectativas específicas. O mesmo tipo de comentário aplica-se ao chamado mercado de trabalho. Tradicionalmente já se reconhece a relevância de organizações como sindicatos e das leis trabalhistas (ou de sua ausência). Alguns autores destacam também normas sociais ou convenções, especialmente dentro das firmas e referentes, por exemplo, ao esforço dos empregados e à justiça de seu tratamento pelos superiores hierárquicos.

Menos comumente reconhecidas, mas igualmente relevantes, são as instituições informais envolvendo decisões sobre o quanto investir e o quanto produzir em mercados de bens. Nesses mercados, pode-se falar também de instituições informais envolvendo, por exemplo, mark-up pricing em várias estruturas de mercado, formas de gerenciamento e procedimentos contábeis, bem como padrões de consumo. Frequentemente trata-se aí de comportamentos em busca de vantagens pecuniárias. Finalmente, mas não menos importante, pode-se falar de um tema ainda pouco explorado: instituições informais na economia como disciplina, que podem influenciar ou ter como contrapartida instituições na economia como objeto.

\section{Disciplinas Definidas por Práticas?}

Uma outra alternativa para definir economia e sociologia é baseada em práticas. Jacob Viner supostamente afirmou (em conversas, mais provavelmente que por escrito) que 
a economia é o que economistas fazem. Muito mais recentemente, Fourcade sugeriu: “[p]araphrasing Jacob Viner's little phrase about economics, we should perhaps simply and modestly say that today economic sociology is what economic sociologists do" (Fourcade 2007: 1018). Será então que uma definição de economia e sociologia econômica em termos de práticas implica uma separação clara entre elas? Ao examinar as abordagens adotadas e os objetos gerais de estudo da economia e da sociologia econômica, percebe-se que há importantes semelhanças entre as práticas de economistas e sociólogos. Naquilo que fazem e como o fazem, alguns economistas se parecem consideravelmente com alguns sociológos econômicos e vice-versa.

Por outro lado, há também diferenças. Os objetos mais específicos de estudo - todos sociais e econômicos ao mesmo tempo - escolhidos pelos praticantes de cada uma podem variar. Também pode ser diferente a composição dos conjuntos dos tipos de abordagem que existem na economia e na sociologia econômica, em particular o peso relativo que essas abordagens têm em cada um desses dois campos acadêmicos a cada momento - como de fato é o caso em vários momentos, incluindo o atual. Em boa medida, essas diferenças podem ser descritas como diferenças entre as instituições que caracterizam a prática da economia como disciplina e da sociologia econômica como uma subdisciplina, respectivamente - por distinção com as instituições da economia como objeto de ambas. Há padrões socialmente compartilhados de pensamento sobre o que estudar e como estudar. No entanto, esses padrões não são compartilhados por todos os economistas ou por todos os sociólogos econômicos, mas sim por comunidades dentro dessas populações. Defender a concepção da economia como uma disciplina que estuda o processo de provisão social não implica necessariamente uma crítica à célebre definição atribuída a Viner, nem à sua paráfrase aplicada à sociologia econômica. Uma razão para isso, como já implicado por comentários anteriores, é que a referência à provisão social não implica diferenciar conceitualmente a economia de outras disciplinas das ciências sociais, quando essas se dedicam a assuntos econômicos, enquanto a avaliação das práticas adotadas pode de fato revelar algumas diferenças, ao lado de semelhanças.

\section{Comentários à Guisa de Conclusão}

Não são abordagens que definem adequadamente a economia ou outras disciplinas das ciências sociais, em particular a sociologia. Cada uma dessas disciplinas contém diferentes abordagens dentro de seu interior e há abordagens semelhantes em diferentes disciplinas. Uma maneira melhor de definir essas disciplinas é baseada em objetos de estudo: a sociologia estuda o social e a economia estuda o econômico. Essa forma de definição aproxima bastante as duas disciplinas. O econômico é social e, em particular, 
institucional. Isso vai bem além do fato razoavelmente óbvio e superficial de que o econômico varia conforme o ambiente social, de tempos em tempos e de lugar em lugar. Nem se trata somente de acrescentar o fato de que o ambiente social ou as instituições influenciam os fins que os agentes econômicos perseguem - e que numa certa visão de economia os economistas poderiam tomar como dados (o que justificaria a divisão de trabalho entre sociologia e economia vislumbrada por Talcott Parsons há várias décadas, tal como descrita por Hodgson, 2001: 196). Como o econômico é social, há uma importante interseção entre os objetos de estudo das duas disciplinas. Na medida em que for possível identificar o social não econômico, a sociologia teria um objeto de estudo mais amplo que a economia. A interseção entre ambas em termos de objeto de estudo corresponderia à economia e à sociologia econômica, entendida como a parte da sociologia que estuda o econômico.

Não haveria então diferença entre a economia e a sociologia econômica? Não, mas apenas em termos do objeto mais amplo de estudo. Isso deixa espaço para outras diferenças, como, por exemplo, aos objetos mais específicos de estudo e à composição dos conjuntos dos tipos de abordagem que existem na economia e na sociologia econômica em determinado momento. Essas diferenças existem de fato hoje. Elas são compatíveis com uma definição pragmática de economia e de sociologia econômica, embora isso também não leve a uma separação completa entre as disciplinas. Alguns praticantes de uma disciplina estudam coisas parecidas e de modo parecido com aquilo que fazem alguns praticantes de outra disciplina. Os argumentos desenvolvidos ao longo deste texto sugerem que a principal distinção a estabelecer é uma entre abordagens e não entre disciplinas, ao menos no caso da economia e da sociologia (econômica). ${ }^{14}$ Comparar e, quando for o caso, contrastar ou combinar abordagens é crucial para o debate acadêmico e para o avanço do conhecimento. Isto ajuda cada pessoa ou cada conjunto de pessoas a adotar a abordagem ou a combinação de abordagens que achar melhor, qualquer que seja a origem disciplinar dessa abordagem ou dessa combinação de abordagens.

A comparação entre as diferentes abordagens nas diferentes disciplinas tem levado alguns economistas e sociólogos a uma avaliação crítica da economia neoclássica, em geral e aplicada ao estudo das instituições em particular. Nesse sentido, há uma convergência entre parte considerável da nova sociologia econômica, o institucionalismo organizacional e diversas correntes heterodoxas de economistas. A esse respeito, cabe aqui comentar a visão de André Orléan (2005) sobre a relação entre a economia e a sociologia econômica. Para ele, a unidade da economia e outras disciplinas das ciências sociais resulta do fato de todas tratarem do mundo social. Orléan, assim como outros convencionalistas franceses, tem dado excelentes contribuições para desnaturalizar

\footnotetext{
${ }^{14}$ Paul DiMaggio (1998) argumenta algo semelhante com relação não à economia e sociologia, mas aos novos institucionalismos na economia, sociologia e ciência política.
} 
o mundo econômico. Ele explicita e critica hipóteses fundamentais da economia neoclássica e de seu subconjunto walrasiano, a teoria do equilíbrio geral. Até aí vários economistas heterodoxos, sociólogos econômicos e institucionalistas organizacionais podem concordar com certa facilidade. Orléan argumenta ainda que, em vez de ser uma abordagem associal, abstrata e com ligações tênues com a realidade, como sugerem alguns críticos, a teoria neoclássica ou sua variante walrasiana pressupõe implicitamente um intenso e já concluído processo (ou, no termo escolhido por Orléan, um intenso "trabalho") social de objetivação ou naturalização da realidade. Isso é necessário para que os agentes econômicos enxerguem facilmente a realidade de uma maneira comum e específica. No caso da teoria walrasiana, em particular, Orléan destaca uma hipótese sobre a lista de bens e sua qualidade e outra hipótese sobre a lista de estados futuros, sendo ambas as listas supostas de conhecimento comum a todos os indivíduos. A teoria nada diz sobre o processo que levaria a isso, implicitamente supondo que isso se imporia naturalmente aos agentes. Para Orléan, o mundo descrito pela abordagem neoclássica seria um mundo social.

De certo ponto de vista isso também parece razoável e é conciliável com as críticas que apontam a associalidade da teoria neoclássica, se essas críticas forem vistas como dirigidas ao que está explícito na teoria, enquanto Orléan aponta a sociabilidade que está implícita em algumas hipóteses neoclássicas ou walrasianas cruciais. No entanto, Orléan parece ir além e sugerir que o mundo dos modelos econômicos neoclássicos pode ser pensado como "uma aproximação do mundo social real" (Orléan 2005: 283), um caso particular. Tal sugestão é mais controversa. Isso talvez possa ser dito sobre certos modelos neoclássicos específicos, mas apenas em situações em que o ambiente social se revele tão influente sobre os indivíduos que eles, por exemplo, tomem o futuro como predeterminado na forma de uma lista conhecida de eventos que a ação dos indivíduos é incapaz de alterar ou suponham conhecida e eternamente imutável a lista de bens e sua respectiva qualidade. Como hipótese geral, no entanto, supor um mundo social com tanto poder de influenciar os indivíduos parece tão irrealista quanto supor um mundo associal.

Se a abordagem neoclássica tem problemas, mesmo quando relida de modo que explicita seus requerimentos de socialização dos indivíduos, o que constitui uma melhor alternativa? No estado da arte atual em economia e em sociologia, talvez nenhuma corrente de pensamento isolada ou mesmo nenhuma disciplina isolada seja capaz de fornecer uma abordagem suficientemente adequada e ampla a todas as questões econômicas importantes. Se este for de fato o caso (e é essa a visão defendida aqui), nosso conhecimento poderá avançar se combinarmos contribuições de diferentes abordagens e de diferentes disciplinas. Ao mesmo tempo, não é trivial fazer isso de modo rigoroso e relevante. As 
abordagens existentes que são críticas à economia neoclássica nem sempre convergem quanto a algo positivo, que vá além do compartilhamento dessa postura negativa.

Há, portanto, o risco de criar híbridos incoerentes. Felizmente, é possível encontrar em várias dessas abordagens algumas ideias semelhantes e, de modo mais importante para a combinação de diferentes contribuições, outras ideias compatíveis e complementares entre si. Essa possibilidade existe em especial no que se refere justamente ao estudo de um dos aspectos cruciais do social-econômico: as instituições.

Os sociólogos econômicos parecem conhecer relativamente pouco das abordagens de economistas não mainstream às instituições. Isso é bastante compreensível, em razão não apenas da especialização disciplinar, mas sobretudo do próprio fato de que essas abordagens gozam de menos prestígio e influência entre os economistas - e, por isso mesmo, são menos conhecidas entre os próprios economistas em seu conjunto. Algumas dessas abordagens não adotam qualquer rótulo de economia institucional ou institucionalista e por isso talvez sejam ainda menos conhecidas por outros interessados em instituições. É o caso, por exemplo, da economia pós-keynesiana, da escola francesa da regulação, da economia neoschumpeteriana e de certos ramos da escola austríaca.

De sua parte, os economistas têm um conhecimento limitado sobre o que está sendo estudado fora de departamentos de economia, o que seguramente inclui assuntos relevantes e autores de boa qualidade - muitas vezes dentro da mainstream de outras disciplinas, ou seja, em universidades prestigiosas, com financiamento de grandes fundações de pesquisa, etc. No caso das investigações sobre instituições, fora da economia como disciplina também tem havido nas últimas décadas uma renovação de abordagens institucionalistas, além de outras correntes de pensamento possivelmente interessantes sem esse rótulo. Um exemplo pertinente, além da já mencionada sociologia econômica, é o institucionalismo nos estudos organizacionais (também dividido em novo e velho, com pontes e interseções entre eles). ${ }^{15}$ Esse institucionalismo organizacional, como também é conhecido, é interdisciplinar, frequentemente praticado por pesquisadores dentro de escolas de administração e bastante sociológico em orientação (nesse sentido, quando estuda organizações econômicas, o institucionalismo organizacional tem uma interseção com a sociologia econômica).

Trocas intelectuais mais frequentes entre os proponentes dessas diferentes abordagens seriam benéficas para todos os envolvidos. Em termos de sugestões para uma agenda de pesquisa, podem ser destacados dois conjuntos de questões relativas às instituições e inter-relacionadas entre si. O primeiro diz respeito à interseção entre instituições e cognição. Foram mencionadas acima duas viradas importantes na disciplina da economia:

\footnotetext{
${ }^{15}$ Ver, por exemplo, Scott (2008) e os volumes editados por Powell e DiMaggio (1991) e Greenwood et alli (2008).
} 
uma institucional e outra cognitiva. Agora é preciso avançar rumo a um entendimento mais institucional da cognição, ou seja, a um entendimento melhor do papel cognitivo das instituições. As instituições fornecem informações, incorporam conhecimento prático e, sobretudo ao incluir modelos mentais compartilhados, influenciam a cognição de modo profundo, na seleção, organização e interpretação de informações. É especialmente esse papel cognitivo profundo que nos leva além de uma abordagem individualística da cognição (criticada inclusive por Knight e North, 1997: 217), além de aproximar a economia da sociologia econômica e do novo institucionalismo organizacional, que destaca o que Richard Scott (2008) chama de pilar cultural-cognitivo das instituições. O segundo bloco de questões concerne os desafios envolvidos em reconhecer os tipos profundos de influência das instituições sobre os agentes econômicos (individuais e coletivos) e simultaneamente dar espaço para que esses agentes desviem de alguns padrões estabelecidos - ao mesmo tempo em que continuam seguindo outros - e causem mudanças endógenas. Um maior intercâmbio interdisciplinar poderia contribuir também para reduzir ou mesmo eliminar barreiras departamentais que, como as próprias instituições (ou como exemplos de instituições, dentro da academia), nada têm de inevitável ou natural, nem de necessariamente mais eficiente que outras alternativas.

\section{Referências}

Aglietta, M., Orléan, A. (2002), La Monnaie entre Violence et Confiance. Paris: Odile Jacob.

Akerlof, G. (1984), An Economic Theorist's Book of Tales. Cambridge: Cambridge University Press.

Aoki, M. (2001), Toward a Comparative Institutional Analysis. Cambridge, MA: MIT Press.

Becker, G. (1976), The Economic Approach to Human Behavior. Chicago: University of Chicago Press.

Beckert, J. (1996), What is sociological about economic sociology? Uncertainty and the embeddedness of economic action. Theory and Society. v. 25, n. 6, p. 803-840.

Coleman, J. (1994), A Rational Choice Perspective on Economic Sociology. In: Smelser, N., Swedberg, R. (Org.). The Handbook of Economic Sociology. Princeton: Princeton University Press, p. 166-180.

Dequech, D. (2003), Uncertainty and economic sociology. American Journal of Economics and Sociology. v. 62, n. 3 , p. $509-532$.

Dequech, D. (2006), The New Institutional Economics and the theory of behaviour under uncertainty. Journal of Economic Behavior and Organization. v. 59, n. 1, p. 109-131.

Dequech, D. (2007-2008), Neoclassical, mainstream, orthodox, and heterodox economics. Journal of Post Keynesian Economics. v. 30, n. 2, p. 279-302.

Dequech, D. (2009), Institutions, social norms, and decision-theoretic norms. Journal of Economic Behavior and Organization, v. 72, n. 1, p. 70-78.

DiMaggio, P. (1988), The New Institutionalisms: Avenues of Collaboration. Journal of Institutional and Theoretical Economics. v. 154, n. 4, p. 696-705.

Dobbin, F. (2004), The Sociological View of the Economy. In: Dobbin, F. (Org.). The New Economic Sociology: A Reader. Princeton: Princeton University Press, p. 1-48.

Durlauf, S., Young, H. P. (Org.) (1991), Social Dynamics. Cambridge, MA: MIT Press, 2001.

Etzioni, A. Socio-Economics: A Budding Challenge. In: Etzioni, A., Lawrence, P. (Org.). Socio-economics: toward a new synthesis. Armonk, NY: Sharpe, p. 3-7. 
Eymard-Duvernay, F., Favereau, O., Orléan, A., Salais, R., Thévenot, L. (2006), Valeurs, coordination et rationalité: trois thèmes mis en relation para l'économie des conventions. In: Eymard-Duvernay, F. (Org.). L'économie des conventions, méthodes et résultats - Tome I: Débats. Paris: La Découverte, p. 23-44.

Fligstein, N. (2001), The Architecture of Markets. Princeton: Princeton University Press.

Fligstein, N., Dauter, L. (2007), The Sociology of Markets. Annual Review of Sociology. v. 33, p. 105-128.

Fourcade, M. (2007), Theories of Markets and Theories of Society. American Behavioral Scientist. v. 50, n. 8, p. 1015-1034.

Greenwood, R., Oliver, C., Suddaby, R., Sahlin-Andersson, K. (Org.) (2008), The Sage Handbook of Organizational Institutionalism. Thousand Oaks, CA: Sage.

Greif, A. (2006), Institutions and the Path to the Modern Economy. Cambridge: Cambridge University Press.

Gruchy, A. (1987), The Reconstruction of Economics. New York: Greenwood.

Hodgson, G. (1994), The Return of Institutional Economics. In: Smelser, N., Swedberg, R. (Org.). The Handbook of Economic Sociology. Princeton: Princeton University Press. p. 58-76.

Hodgson, G. (2001), How Economics Forgot History. London: Routledge.

Keynes, J. M. The General Theory of Employment, Interest and Money. London: Macmillan.

Keynes, J. M. The General Theory of Employment. Quarterly Journal of Economics. v. 51, n. 2, p. 209-223.

Knight, J., North, D. (1997), Explaining Economic Change: The Interplay Between Cognition and Institutions. Legal Theory. v. 3, n. 3, p. 211-226.

Krippner, G., Alvarez, A. (2007), Embeddedness and the Intellectual Projects of Economic Sociology. Annual Review of Sociology. v. 33, p. 219-240.

Lévesque, B., Bourque, G., Forgues, É. (1997), La Sociologie Économique de Langue Française: Originalité et Diversité des Aproches. Cahiers Internationaux de Sociologie. v. 103, p. 265-294.

Neale, W. (1987), Institutions. Journal of Economic Issues. v. 21, n. 3, p. 1177-1206.

Orléan, A. (1999), Le pouvoir de la finance. Paris: Odile Jacob.

Orléan, A. (2005), La sociologie économique et la question de l'unité des sciences sociales. L'Année Sociologique. v. 55 , n. 2 , p. $279-305$.

Polanyi, K. (1944), The Great Transformation. Boston: Beacon Press.

Polanyi, K. (1957), The Economy as Instituted Process. In: Polanyi, K., Arensberg, C., Pearson, H. (Org.). Trade and Market in the Early Empires. New York: Free Press, p. 243-270.

Powell, W., Dimaggio, P. (Org.) (1991), The New Institutionalism in Organizational Analysis. Chicago: University of Chicago Press.

Savage, L. The Foundations of Statistics. New York: Wiley.

Scott, W. R. (2008), Institutions and Organizations: Ideas and Interests. $3^{\text {rd }}$ ed. Thousand Oaks, CA: Sage.

Sen, A. (1977), Rational Fools: A Critique of the Behavioral Foundations of Economic Theory. Philosophy and Public Affairs. v. 6, n. 4, p. 317-334.

Sen, A. (1985), Goals, Commitment, and Identity. Journal of Law, Economics, and Organization. v. 1, n. 2, p. $341-355$.

Smelser, N., Swedberg, R. (1994), The Sociological Perspective on the Economy. In: Smelser, N.; Swedberg, R. (Org.). The Handbook of Economic Sociology. Princeton: Princeton University Press. p. 3-26.

Steiner, P. (1999), La sociologie économique. Paris: La Découverte.

Swedberg, R. (1997), New Economic Sociology: What Has Been Accomplished, What is Ahead? Acta Sociologica. v. 40 , n. 2 , p. $161-182$.

Swedberg, R. (2003), Principles of Economic Sociology. Princeton: Princeton University Press.

Swedberg, R., Granovetter, M. (2001), Introduction to the Second Edition. In: Granovetter, M., Swedberg, R. (Org.). The Sociology of Economic Life. $2^{\text {nd }}$ ed. Boulder: Westview.

Velthuis, O. (1999), The Changing Relationship Between Economic Sociology and Institutional Economics: From Talcott Parsons to Mark Granovetter. American Journal of Economics and Sociology. v. 58, n. 4, p. 629-649.

Wacquant, L., Calhoun, C. (1989), Intérêt, Rationalité et Culture. Actes de la Recherche en Sciences Sociales. v. 78, p. 41-60. 
Zelizer, V. (2007), Pasts and Futures of Economic Sociology. American Behavioral Scientist. v. 50, n. 8, p. 1056-1069.

Zukin, S., DiMaggio, P. (1990), Introduction. In: Zukin, S., DiMaggio, P. (Org.). Structures of Capital: The social organization of the economy. Cambridge: Cambridge University Press, p. 1-36. 